JHR

33,4

Received 6 September 2018 Revised 1 December 2018 15 December 2018 Accepted 17 December 2018

\section{Effectiveness of the Dual Approach Program to promote sexual abstinence in Thai early female adolescents and improve parent-daughter sexual communication}

\author{
Kultida Hattakitpanichakul \\ Ramathibodi School of Nursing, Faculty of Medicine Ramathibodi Hospital, and \\ Faculty of Nursing, Mahidol University, Bangkok, Thailand \\ Rutja Phuphaibul and Srisamorn Phumonsakul \\ Ramathibodi School of Nursing, Faculty of Medicine Ramathibodi Hospital, \\ Mahidol University, Bangkok, Thailand, and \\ Chukiat Viwatwongkasem \\ Faculty of Public Health, Mahidol University, Bangkok, Thailand
}

\begin{abstract}
Purpose - The purpose of this paper is to examine the effectiveness of abstinence-based sexual education programs delivered in parallel to Thai parents and their early adolescent daughters to promote sexual abstinence and improve communication regarding sexual topics between them and their parents.

Design/methodology/approach - A quasi-experimental design included groups of parent/daughter dyads; Group 1 (controls) $(n=40)$, Group 2 Adolescent Program $(n=40)$ and Group 3 Adolescent Parent Program (APP) $(n=42)$. Outcome measures included parent-adolescent communications and adolescents' sexual abstinence cognitions and intent to abstain from sexual behaviors, measured at five and nine weeks post-programs.

Findings - Generalized estimating equation analyses indicated that the dual program (APP) was more effective in increasing parental communication with their daughters compared with Group $1(p$-value $<0.05)$ and only the daughters in the APP program reported more positive subjective norms, sense of perceived behavioral control and intent to abstain than did Group 1 ( $p$-value $<0.05$ ).

Originality/value - The overarching goal of supporting the development of family environments where female adolescents are able to talk about sexuality is essential for adolescent sexual health promotion. The data provide further evidence that a dual program with simultaneous parent and female adolescent interactive activities over three sessions is superior compared with programs that target either the parents or the adolescents only. Hence, further replication with more parent-daughter dyads and then within more diverse cultures and populations is warranted. Developing and testing a similarly structured program for parents and sons is also required.
\end{abstract}

Keywords Adolescent health, Health promotion, Parent-daughter communication, Sexual health education Paper type Research paper

(C) Kultida Hattakitpanichakul, Rutja Phuphaibul, Srisamorn Phumonsakul and Chukiat Viwatwongkasem. Published in Journal of Health Research. Published by Emerald Publishing Limited. This article is published under the Creative Commons Attribution (CC BY 4.0) licence. Anyone may reproduce, distribute, translate and create derivative works of this article (for both commercial and non-commercial purposes), subject to full attribution to the original publication and authors. The full terms of this licence may be seen at $\mathrm{http}: / /$ creativecommons.org/licences/by/4.0/legalcode

The study was partially funded by the Graduate Studies of Mahidol University Alumni Association. 


\section{Background}

Over the past two decades and across multiple countries, sexual behavior patterns have continued to change with earlier ages of sexual debut, increasing numbers of multiple partners, decreased condom use at sexual debut and rising prevalence of teenage pregnancy and sexually transmitted infections (STIs)[1-6]. These changes are more pronounced among female adolescents than males[7]. Correlates associated with engaging in sexual intercourse include increasing age, male gender, poor school attendance/performance and poor parental relationships/communication patterns[8-11]. According to Thai survey data, the prevalence of sexual intercourse among adolescent's ranges from 10 to 18.2 percent, depending on the age of the survey participants[10-12]. A report by the Department of Disease Control of Thailand has shown the rate of STIs in adolescents to be 143.44 per 100,000 youths[13]. It has further been posited that increased economic prosperity and exposure to western media in Thailand has eroded traditional religious and cultural values. Consequently, adolescents experience increased sexual awareness, key gaps in knowledge about sexuality-related topics, limited parental input and increased risk-taking[14].

Sex education is an important component in the transition from childhood to adolescence. In general, sex education programs cover two broad topics: sex-related anatomical and physiological information and sexual behaviors. In terms of sexual behaviors, two overarching philosophical frameworks have been described: total premarital abstinence or alternatively, harm reduction/comprehensive-based programs. Abstinence-based programs often reflect religious teachings and traditional societal beliefs and values[14]. Most topics in such programs focus on the physical changes in puberty and the value of abstinence. As in many other societies, considerable gender differences exist concerning acceptable adolescent behaviors in Thai society. Consequently, Thai girls have increased social expectations to be abstinent during their adolescence and are more open to criticism for engaging in sexual activity[14]. Harm reduction in the context of sex education refers to policies and programs aimed at minimizing the negative social, economic and health-related consequences of sexual behaviors without necessarily insisting on abstinence[15]. However, neither of these frameworks can report total success in preventing adolescents from the dangers of unsafe sexual intercourse[7, 38, 16]. In addition, abstinence-based programs focus on younger adolescents (aged 12-14 years) in the belief that they are less likely to have already engaged in sexual behaviors[16-19].

Although the initial establishment of school-based sex education met with resistance from parents who felt that the school was usurping parental responsibility and the natural transmission of family values[20], school-based programs are now well-established in most countries. Programs vary between strict abstinence based to comprehensive programs or even programs with components of both philosophies. Several sexual health education programs exist in Thailand. Like other international data, results have been modest in terms of reducing pregnancies or sexual risk prevention[17, 21-23]. Multiple studies[9, 18, 24, 25] have shown that parental involvement within the home and with school-based sex education programs can influence adolescents' sexual behavior. Positive communication between adolescents and parents and/or parental participation in school-based education have produced multiple positive outcomes, including more positive attitudes toward abstinence[9], safer sexual behaviors[24], decreased risk of multiple sex partners[25] and postponement of vaginal sex[18]. Public health nurses (PHNs) (or "school nurses") have long been involved in sexual health promotion in school settings, although the most common student access is through referral[26]. Evaluations of PNH roles have suggested that more active involvement is needed[26, 27]. Most PHNs advocate comprehensive sex education programs[28]. A Thai study reported the positive results of a nurse-led, school-based cognitive behavioral therapy-based program for depressed adolescents[29]. However, the researchers found no studies that discussed the school-based sex education curriculum co-taught by teachers and PHNs, or nurse-led school-based sex education programs. 
JHR

33,4

The roles of cultural and societal beliefs and values are emphasized as a key ecological factor in adolescents' risky sexual behaviors[9, 18, 30-32]. A Thai study[14, 33] reported competing influences between traditional parental disapproval and access to western-based pornographic media to be associated with pre-coital behavior, the age of sexual debut and refusal self-efficacy. A meta-analysis of parent-adolescent sexual communication provides evidence that mothers can provide some protection against unsafe sexual behaviors, especially for daughters, and supports the development of gender-specific educational materials and programs for mothers, fathers, daughters and sons[24]. Previous Thai research[34, 35] reported that daughters are more likely than sons to have discussions with their parents, especially mothers, about sexual behaviors. However, studies indicated that many Thai parents still preserve traditions and beliefs against the sexual topic discussions between parents and their adolescents[36, 37].

The aim of this study was to test the effectiveness of a culturally appropriate nurse-led parent sex education program combined with a parallel early adolescent program focusing on promoting sexual abstinence in 10-13-year-old girls. The hypothesized outcome for parents was increased communication about sexual issues with daughters. On the other hand, the outcomes for adolescents were higher scores on four domains of sexual abstinence cognitions (defined as thoughts, opinions and perceptions related to attitudes; subjective norms; perceived behavioral control and intention toward sexual abstinence). While individual family dynamics (parent-adolescent relationship quality, parental monitoring and marital relationships) are acknowledged as important contributors to the degree of sexuality-related discussion within a family, this study focused on the effectiveness of a dual parent-adolescent program. The research team based the program on principles and learning activities that were generally applicable to most families. The parent program focused on increasing knowledge of and comfort with discussing sexual topics with daughters. The theory of planned behavior guided the development of the parental program[38]. This theory considers that the relationship between individual beliefs based on positive attitudes, subjective norms for specific behaviors and perceived behavioral control can predict and lead to changes in behavioral intentions. Researchers used this theory to develop sex education programs[23, 31], while other groups have used social learning theory[17], positive youth development[21] and social cognitive learning theory[29]. The decision to use this theory was guided by previous Thai research that reported parental sexual communication influenced changes on sexual abstinence intention through behavioral beliefs, normative beliefs and behavioral control beliefs among female adolescents[36]. The research team also developed a parallel educational program for adolescent girls based on the same theory of planned behavior. The parallel program was designed to augment the school-based standardized sexual health section of the health courses taught by teaching staff (2-h sessions focused on expected pubertal anatomical and physiological changes as well as sexual behaviors).

Thus, the research team developed the Dual Approach Program based on the theory of planned behavior adapted from a previous Thai study[39] for early female adolescents and parents (Figure 1). The researchers integrated effective approaches through specific activities to support developing sexual abstinence beliefs in adolescent girls and the modification of sexual communication behaviors of parents. An abstinence-based program was chosen as the target group of adolescent girls aged 10-13. Previous research[40, 41] showed that this age group in Thailand has low levels of sexual behaviors making this age group optimal for promoting early parental comfort and skills in discussing sexual issues. The age group is also optimal for promoting early intention to abstain from sexual behaviors among young adolescents.

\section{Methods}

A quasi-experimental research design was used to test the effectiveness of the Dual Approach Program with both adolescents and parents. The outcome measures for the adolescent girls included sexual abstinence cognitions, attitudes toward sexual abstinence, subjective norms 


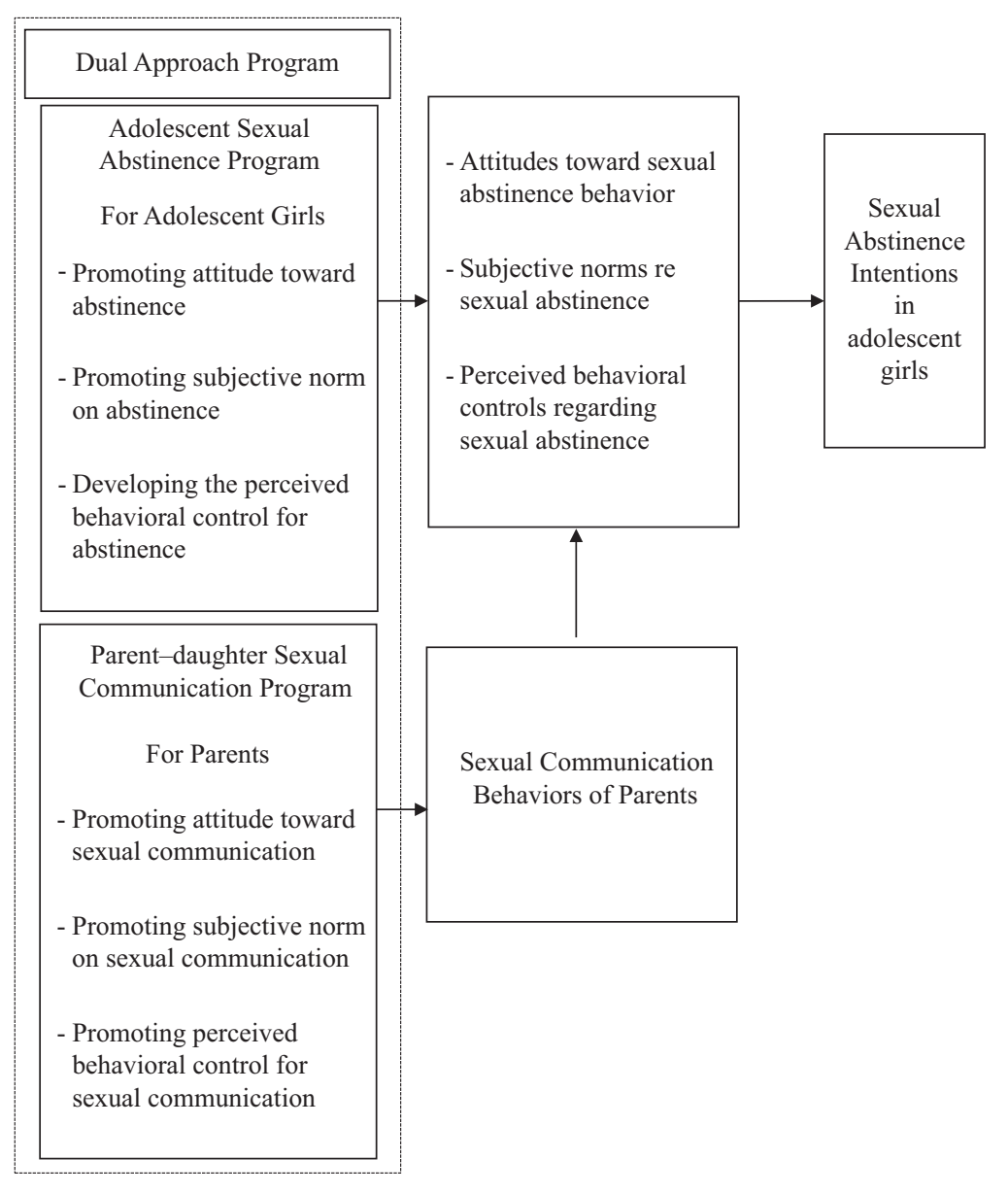

Effectiveness of the Dual Approach Program

283

Figure 1. Conceptual framework of the study

and perceived behavioral control. For parents, the outcome measures were parent-daughter sexual communication behavior scores on a modified Parent-Puberty Child Sexual Communication Questionnaire[42]. The researchers compared baseline measures to measures at different post-program time periods, depending on group assignment (Group 1: Control Group; Group 2: Adolescent Program Only (AP); and Group 3: Dual Approach Program (APP)). Sealed envelopes were provided to all participants for collecting questionnaires.

From a list of 22 mixed gender public schools in metropolitan Bangkok that were similar in terms of school size, number of students $(>1,000)$ and standardized curriculum in sexual health education, the researchers randomly selected three public schools and assigned each of the schools to one of the three groups. All three of the randomly selected schools agreed to participate. Each school formed one of the three groups to limit shared communication about the program across groups. The inclusion criteria for potential adolescent participants were as follows: female students aged 10-13 years old, studying in Grade 7 in public schools in Bangkok and living with their parents. The inclusion criteria for parents included: caregivers whose female adolescent family members were participants in the study and lived in the same residence. To limit the size of the discussion groups and have a single person completing the home-based activities and 
JHR

33,4

Table I.

The detail of sessions in the Dual Approach Program questionnaires, one parent or substitute family caregiver was invited to attend the program, the choice being left up to the families.

The researchers calculated the required sample size by using the formula for a repeated measure design[43]. The $\alpha$ for the test was set at 0.05 to achieve a power of 0.80 . The average effect size from previous similar studies on adolescent intervention[44] and parent intervention[37] was 0.8 . Thus, the calculated sample size was 40 parent/daughter dyads per group (total of 120 families).

The Dual Approach Program (APP) was developed specifically for young adolescent girls and parents in the Thai social context. The objectives and activities of the three sessions for parents and for adolescents are listed in Table I. The Dual Approach Program consisted of three sessions in the parent program combined with three sessions in the adolescent program made of up 60-90 min per session. The three sessions occurred over a four-week period (Figure 2). The research team held two parent group sessions on Saturdays and Sundays to facilitate families and increase individual participation. Then the team held four adolescent group sessions on Wednesdays. Two facilitators and an observer from the research team attended each group session. Prior to initiating the program, the content validity of the program was examined by three experts with experience in adolescent sexual health and the TPB framework. The program was also pilot tested among 33 parent/daughter dyads with similar characteristics to the expected study participants.

Session Principle Details of session

Adolescent Program

Session I Promoting a positive Exploring attitudes toward abstinence

attitude toward Providing information and discussion based on a video clip related to sexual sexual abstinence abstinence and the consequences of early sexual activity. This 8-minute publicly available video clip titled "Is love to share?" was developed by Thai Health Organization and features a short play which reflects common situations about sexual risk behaviors and ends with presenting the consequences of sexual intercourse among early adolescents

Session II Increasing Group sharing their experiences regarding peers' opinions about sexual subjective norms on abstinence

sexual abstinence Providing homework assignment to interview their parents regarding their attitudes about the adolescents' sexual behavior

Session III Developing Small group discussions regarding strengths and barriers involved with perceived behavioral sexual abstinence intention and setting goals and planning strategies to control for sexual achieve sexual abstinence intention

abstinence: activities Role playing allowed participants to practice potential strategies supporting sexual abstinence

Ongoing feedback was provided by the facilitators

Parent Program

Session I Promoting attitude Providing information and viewing a video clip (developed specifically for toward sexual this study showing model conversation between researchers and communication consenting parents) that discusses the importance of good communication Providing examples of parents engaged in open communication with their daughters about sexual health, followed by group discussion

Session II Increasing Writing letters to their daughters expressing their desire to talk about subjective norms for sexual issues, supporting sexual abstinence among school ages for their sexual communication parents received from their daughters upon receipt of these cards

Session III Promoting perceived Practicing by using sample situations (standardized across the two parent behavioral control groups)

for sexual Providing parents' handbooks for practicing at home based on the topic of communication each week's session 


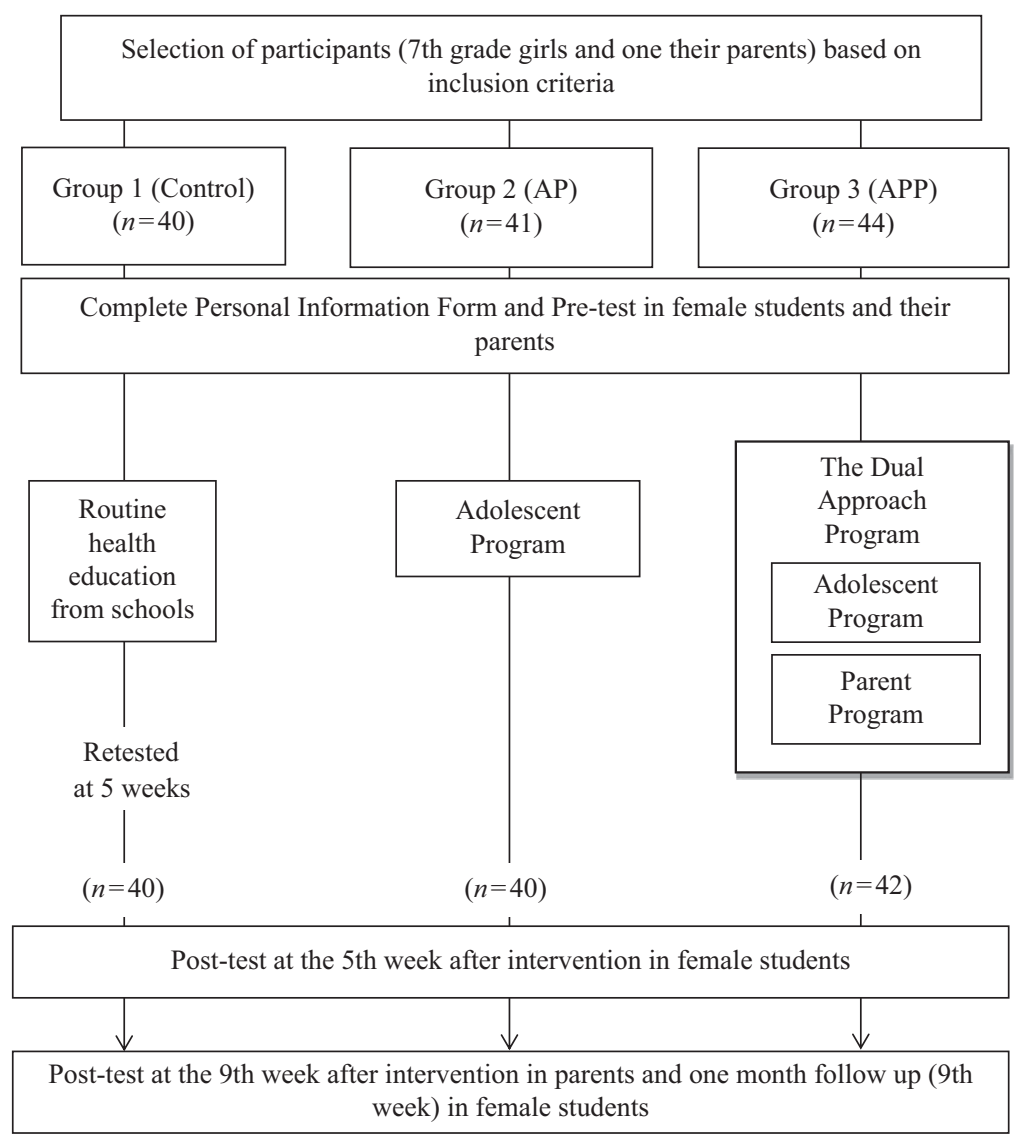
Effectiveness
of the Dual Approach Program

285

Figure 2.

Flow chart of data collection for the Dual Approach Program

The study was approved by the Committee on Human Rights Related to Research Involving Human Subjects, Faculty of Medicine Ramathibodi Hospital, Mahidol University, Thailand (COA No. MURA 2017/408).

\section{Outcome measures}

In addition to collecting socio-demographic information, self-report questionnaires were used to assess the adolescents' perceptions across the four domains (attitudes, increasing subjective norms, perceived behavioral control and intention) and parents' behaviors. The adolescents completed the questionnaires at each time point (at baseline, at five and nine weeks' post-program). The parents completed the questionnaires at baseline and at nine weeks' post-program. The researchers used the following standardized questionnaires, which had been previously translated into Thai [39, 42, 45], to examine the outcome measures.

Parent-daughter Sexual Communication Behavior Questionnaire: consisted of 12 items modified from the Parent-Puberty Child Sexual Communication Questionnaire[42]. Ratings were dichotomous $(0=$ no; $1=$ yes $)$. Higher scores indicating greater parent sexual communication levels. Internal consistency (Cronbach's $\alpha$ ) was 0.86 for this questionnaire.

Sexual Abstinence Questionnaire[39, 45]: the researcher modified the instrument from focusing exclusively on abstinence to assessing the adolescents' sexual abstinence cognitions 
JHR

33,4

across the four domains of interest. The content validity index of this questionnaire was 0.89 : Attitudes toward sexual abstinence were measured using two subscales: Behavioral Beliefs toward Sexual Abstinence contained seven items with scores ranging from 1 (strongly disagree) to 5 (strongly agree); and Outcome Evaluations toward Sexual Abstinence were measured on seven items with scores ranging from $1=$ "extremely bad" to $5=$ "extremely good." Scores were summed with higher total scores representing more positive attitudes toward sexual abstinence. In this study, Cronbach's $\alpha$ was 0.82 for this measure; Subjective Norms were also assessed using two subscales: Normative Belief toward Sexual Abstinence contained seven items with scores ranging from 1 (definitely should not) to 5 (definitely should); and Motivation to Comply with Sexual Abstinence were evaluated by seven items with scores ranging from $1=$ "definitely do not do" to $5=$ "definitely do." Scores were summed with higher total scores representing stronger subjective norms toward sexual abstinence. Cronbach's $\alpha$ was 0.92 for this measure; Perceived Behavioral Control was measured using two subscales; Control Beliefs toward Sexual Abstinence contained five items with scores ranging from 1 (very unlikely) to 5 (very likely); and Powers of Control toward Sexual Abstinence were measured on five items from 1 (strongly disagree) to 5 (strongly agree). Scores were summed with higher total scores reflecting greater perceived behavioral control for sexual abstinence. Cronbach's $\alpha$ of this measure in this study was 0.88 ; and Sexual Abstinence Intention or individual determination to actively refrain from sexual intercourse during the current school year. The scores for the above four items ranged from 0 percent (no definite intention) to 100 percent (definite intention). Higher percentages reflected greater sexual abstinence intention. Cronbach's $\alpha$ for this measure in the study was 0.78 .

\section{Data analysis}

The researchers analyzed the data by using the Statistical Package of Social Sciences Version 18.0 and set statistical significance at $p$-value $\leqslant 0.05$. The researcher also conducted an analysis of variance (ANOVA) and $\chi^{2}$ analyses to identify statistically significant differences among the three groups on socio-demographic characteristics. Generalized estimating equations (GEE) were used to test the hypotheses regarding the effects of the intervention groups on parents' sexual communication. GEE was also used to compare sexual abstinence cognitions among female students across the three groups (controls, AP and APP) across time. For the GEE calculations, the researchers used the scores of the control group at baseline as the reference value to eliminate any potential effects from the experimental groups sharing information about the program with the control group. Although there were two grandmothers in each group, the researchers considered them as parents in the context of the data analysis.

\section{Results}

A total of 40 parent/daughter dyads from Groups 1 and 2 and 42 dyads from Group 3 attended all sessions and completed all questionnaires. The attrition rate was 2.4 percent. Most students were 12 or 13 years old (95 percent of the girls in all groups), first-born children and living with both parents. The researchers found no differences among the demographic characteristics of the three groups of girls (by age, grade point average or family status), nor across the groups of parents (by age, gender, marital status or education). The average parental age across the groups ranged between 41.7 and 43.9 years. Three-quarters of the parents who participated in this study were mothers. Most of the parents worked outside the home and approximately onethird of each group lived below the nationally defined poverty line.

The research team found no differences in the scores on the modified Parent-Puberty Child Sexual Communication Questionnaire across the groups at baseline. However, at the one-month post-intervention (Week 9), the communication scores of the parents in Group 3 were significantly higher than those of the other two groups. This finding suggests that, even after homework assignments were no longer prompting communication, parents continued to report that parent-daughter communications regarding sexual issues were 
ongoing and they felt more confident and comfortable during the conversations. The results of the GEE modeling suggest that participating in the Dual Approach Program was a strong predictor of an increase in parents' sexual communication behavior scores. The sexual communication scores of the parents in Group 2 (who received only the Adolescent Program) were not significantly different from those in Group 1 (Control Group) at Week 9 (Table II). The data from Group 2 essentially served as a negative control in the comparisons between Groups 1 and 3.

The researchers observed no significant differences in the comparisons of scores at baseline for the four domains of the girls' sexual abstinence cognitions across the three groups. Using Group 1 scores at baseline as the reference values, significant changes in some of the scores emerged for both Groups 2 and 3 at Week 5 (Table III) and were maintained at Week 9 (Table IV). At Week 5 , the scores of the adolescents in Group 2 reflected no changes in subjective norms and trends for changes in attitude and intentions to abstain; however, there was a significant positive change in perceived behavioral control. By Week 9, the positive changes in intention scores were significantly different between Groups 1 and 2. Group 3 scores across all four domains showed the most positive changes compared to Group 1. The researchers observed significant changes in scores across three of the domains at both time points, while changes in scores in relation to attitudes were most significant.

\begin{tabular}{lcccccc}
\hline Variables & Baseline $\mu(\mathrm{SD})$ & Posttest $\mu(\mathrm{SD})$ & $\beta$ & SE & $95 \% \mathrm{CI}$ & $p$-value \\
\hline \multicolumn{2}{l}{$\begin{array}{l}\text { Sexual communication behavior of parents } \\
\text { Week 9 }\end{array}$} & & & & & \\
Group 1 (Control) & $8.03(3.32)$ & $7.83(3.54)$ & - & - & - & - \\
Group 2 (AP) & $7.98(3.75)$ & $7.93(3.30)$ & 0.15 & 1.04 & {$[-1.88,2.18]$} & 0.890 \\
Group 3 (APP) & $6.95(3.82)$ & $9.60(2.46)$ & 2.84 & 1.00 & {$[0.89,4.80]$} & $0.004 * *$
\end{tabular}

Notes: AP, Adolescent Program; APP, Adolescent Parent Program; $\beta$, unstandardized beta coefficient; CI, confidence interval. $* * p<0.01$
Effectiveness of the Dual Approach Program

Table II.

Comparisons over time using generalized estimating equations to evaluate the effect of the Dual Approach

Program on parents' sexual communication behaviors

\begin{tabular}{|c|c|c|c|c|c|c|}
\hline Variables & Baseline $\mu$ (SD) & Week $5 \mu$ (SD) & $\beta$ & SE & $95 \% \mathrm{CI}$ & $p$-value \\
\hline \multicolumn{7}{|l|}{ Attitude } \\
\hline Group 1 & 102.18 (19.16) & $116.30(29.89)$ & - & - & - & - \\
\hline Group 2 (AP) & $109.60(14.95)$ & $125.23(22.64)$ & 1.50 & 5.68 & {$[-9.63,12.63]$} & 0.792 \\
\hline Group 3 (APP) & 102.19 (18.33) & $126.88(23.66)$ & 10.57 & 35.50 & {$[-0.21,21.34]$} & 0.055 \\
\hline \multicolumn{7}{|l|}{ Subjective norm } \\
\hline Group 1 & $77.83(40.33)$ & $80.80(36.75)$ & - & - & - & - \\
\hline Group 2 (AP) & $75.73(24.98)$ & $98.83(26.89)$ & 15.13 & 10.06 & {$[-4.60,38.84]$} & 0.133 \\
\hline Group 3 (APP) & $75.36(26.81)$ & $108.14(35.75)$ & 29.81 & 9.94 & {$[10.33,49.29]$} & $0.003^{* *}$ \\
\hline \multicolumn{7}{|c|}{ Perceived behavioral control } \\
\hline Group 1 & 72.18 (31.75) & $70.10(29.24)$ & - & - & - & - \\
\hline Group 2 (AP) & $69.38(31.24)$ & $81.23(33.95)$ & 13.93 & 5.77 & {$[2.62,25.23]$} & $0.016^{*}$ \\
\hline Group 3 (APP) & $72.26(26.90)$ & $92(26.22)$ & 21.81 & 5.53 & {$[10.98,32.65]$} & $<0.001 * *$ \\
\hline \multicolumn{7}{|l|}{ Intention } \\
\hline Group 1 & 72.69 (19.84) & 75.06 (17.72) & - & - & - & \\
\hline Group 2 (AP) & 74.06 (12.28) & 82.17 (12.23) & 5.73 & 3.32 & {$[-0.78,12.24]$} & 0.084 \\
\hline Group 3 (APP) & 72.05 (17.74) & 87.02 (13.23) & 12.60 & 3.89 & {$[4.97,20.23]$} & $0.001^{* *}$ \\
\hline
\end{tabular}

Notes: AP, Adolescent Program; APP, Adolescent Parent Program; $\beta$, unstandardized beta coefficient; CI, confidence interval. $* p<0.05 ; * * p<0.01$

Table III. Comparisons at Week 5 using generalized estimating equations to evaluate the effect of the Dual Approach Program on adolescents' sexual abstinence cognition scores using the control group at baseline as the reference scores 


\begin{tabular}{|c|c|c|c|c|c|c|}
\hline$\underline{\text { Variables }}$ & Baseline $\mu$ (SD) & Week $9 \mu$ (SD) & $\beta$ & $\mathrm{SE}$ & $95 \% \mathrm{CI}$ & $p$-value \\
\hline \multicolumn{7}{|l|}{ Attitude } \\
\hline Group 1 & 102.18 (19.16) & 118.82 (30.79) & - & - & & - \\
\hline Group 2 (AP) & 109.60 (14.95) & $130.00(21.70)$ & 3.75 & 5.93 & {$[-7.87,15.37]$} & 0.527 \\
\hline Group 3 (APP) & $102.19(18.33)$ & $129.50(22.03)$ & 10.66 & 5.76 & {$[-0.62,21.94]$} & 0.064 \\
\hline \multicolumn{7}{|l|}{ Subjective norm } \\
\hline Group 1 & 77.83 (40.33) & 77.88 (26.81) & - & - & & - \\
\hline Group 2 (AP) & 75.73 (24.98) & $91.83(35.75)$ & 16.05 & 10.06 & {$[-3.67,35.77]$} & 0.111 \\
\hline Group 3 (APP) & $75.36(26.81)$ & 109.69 (36.68) & 34.28 & 9.94 & {$[14.81,53.76]$} & $0.001^{* *}$ \\
\hline \multicolumn{7}{|c|}{ Perceived behavioral control } \\
\hline Group 1 & 72.18 (31.75) & $69.10(26.90)$ & - & - & - & - \\
\hline Group 2 (AP) & 69.38 (31.24) & $80.63(33.60)$ & 14.33 & 5.69 & {$[3.33,25.32]$} & $0.011^{*}$ \\
\hline Group 3 (APP) & $72.26(26.90)$ & $94.50(27.66)$ & 25.31 & 5.47 & {$[14.59,36.04]$} & $<0.001^{* *}$ \\
\hline \multicolumn{7}{|l|}{ Intention } \\
\hline Group 1 & 72.69 (19.84) & 74.90 (17.74) & - & - & & - \\
\hline Group 2 (AP) & 74.06 (12.28) & 82.90 (12.25) & 6.86 & 3.30 & {$[0.12,13.06]$} & $0.046^{*}$ \\
\hline Group 3 (APP) & 72.05 (17.74) & 87.44 (13.47) & 13.14 & 3.93 & {$[5.44,20.85]$} & $0.001^{* *}$ \\
\hline
\end{tabular}

Table IV.

Comparisons at Week 9 using generalized estimating equations to evaluate the effect of the Dual Approach Program on adolescents' sexual abstinence cognition scores using the control group as the reference
Notes: AP, Adolescent Program; APP, Adolescent Parent Program; $\beta$, unstandardized beta coefficient; CI, confidence interval. $* p<0.05 ; * * p<0.01$

\section{Discussion}

Improvements in sexual communication between parents and daughters in Group 3 and the statistically significant positive changes in three of the four domains of sexual abstinence cognitions in the adolescents suggest that the Dual Approach Program was more effective than a program targeted only at adolescent girls. The researchers developed the Dual Approach Program based on the theory of planned behavior[38] and applied the program to increase parent-daughter communication and improve daughters' sexual abstinence cognitions. Furthermore, the program provided a structure for the sessions and yielded significant positive changes over time. From our data, the researchers were not able to assess which of the elements of the parent program were responsible for the improved scores. Some previous research[17-19, 21-23] with early adolescents highlighted the positive impacts of similar types of program components, including discussion, role playing, education with games, videos and practicing skills. Other studies that relied on lectures, discussions and demonstrations were ineffective in improving knowledge[46], preventing sexual risk behaviors[17] or improving attitudes about using condoms and pills[47]. Combining all of these strategies and providing active discussion through interactive strategies such as brainstorming, interview games with peers and home-based practice assignments to communicate with daughters proved to be effective for the parents in this study. It is possible that the use of multiple strategies and activities appealed to the broadest range of parental preferences and made the program more adaptable across families, and perhaps across countries and cultures. In addition, the researchers believe that the generalizable strength of the intervention lies in providing a simultaneous parallel program. Previous studies[31, 48, 49] on parental involvement in sexual health programs did not include a parallel daughter program and, therefore, were not able to examine the potential direct effects on daughters' sexual abstinence cognitions as reported by the present study. The data obtained by this study provide supportive evidence that simultaneously supporting parents' sexual communication behaviors may contribute to positive changes in positive attitudes, subjective norms for behavior and perceived behavioral control as described in the adolescent component of the dual program. 
Similarly, the Adolescent Program (as provided to Groups 2 and 3) incorporated multiple strategies to promote positive sexual abstinence cognitions. Highly interactive activities facilitating the group discussions were complemented with a video presentation, an interview-based assignment with peers and parents, the practice of specific skills supporting refusal self-efficacy and seeking support for intention to abstain (as opposed to pressuring girls to wholly avow abstinence). These teaching and learning activities within the Adolescent Program in combination with the ability to express opinions to parents, seek affirmation, openly ask questions or understand parental concerns helped strengthen positive thoughts and beliefs about intended abstinence in this age group. Long-term abstinence was not the stated goal, which may have contributed to the more robust results compared to other abstinence-based programs. Although the design of the study did not allow us to follow these parent-daughter dyads beyond nine weeks' post-program, the Dual Approach Program has set the stage for more open communications across the adolescent years. It is possible that, once the daughters choose to become sexually active, they will do so with an increased likelihood of their ability to discuss any untoward consequences with a parent.

A limitation of this study is in the overall research design. The intervention was developed by nurses and delivered by teams of three nurses for each group of 20 parents or adolescents. The researchers structured the intervention to involve weekly sessions of 60-90 min for four weeks plus home-based assignments to be reviewed by the research team. Thus, the intervention is a relatively time and human resource intensive intervention. The positive results in this initial study suggest that further replication studies are warranted. If further studies confirm the superiority of the Dual Approach Program, it would be important for the school system and PHNs to consider how the program could be integrated into the current school program. Funding considerations and responsibilities would require negotiation across different government ministries. An alternative could be a community-based program with volunteer group facilitators initially trained by PHNs. The program could be administered by a PHN as a health promotion strategy funded by the Ministry of Public Health. Other limitations include the relatively short timeframe for follow-up, the program limitation to girls only and the relatively small sample size considering the numbers of students in the selected schools.

\section{Conclusion}

The Dual Approach Program was more effective in improving parents' sexual communications with daughters and also improved daughters' sexual abstinence cognitions in terms of subjective norms, perceived behavioral control and intention for sexual abstinence compared with the Adolescent Program alone. The increasing rates of risky sexual behaviors in early adolescents are alarming, so the development of successful educational programs is a priority. Parallel-group education programs for parents and adolescents employing multiple interactive teaching and learning strategies should be considered. Although not a component of this initial study, the establishment of more open communication between parents and daughters may have positive sexual health outcomes into later adolescence, irrespective of whether the daughters remain sexually abstinent or not. The specific strategies could be adapted by gender, culture or age, but the overall concept of creating a family environment where parents are comfortable and confident about discussing sexuality with sons and daughters bodes well for the future of adolescent sexual health.

\section{References}

1. Currie C, Nic Gabhainn S, Godeau E, Roberts C, Smith R, Currie D. Inequalities in young people's health: international report from the HBSC 2005/06 Survey. Copenhagen: WHO; 2008.

2. Wellings K, Nanchahal K, Macdowall W, McManus S, Erens B, Mercer CH, et al. Sexual behaviour in Britain: early heterosexual experience. Lancet. 2001 Dec; 358(9296): 1843-50.
Effectiveness of the Dual Approach Program 
3. Wellings K, Collumbien M, Slaymaker E, Singh S, Hodges Z, Patel D, et al. Sexual behaviour in context: a global perspective. Lancet. 2006; 368(9548): 1706-28.

4. Johnson A, Mercer CH, Erens B, Copas AJ, McManus S, Wellings K, et al. Sexual behaviour in Britain: partnerships, practices, and HIV risk behaviours. Lancet. 2001 Dec; 358(9296): 1835-42.

5. The United Nations Children's Fund [UNICEF]. Child poverty in perspective: an overview of child wellbeing in rich countries. Florence: UNICEF; 2007.

6. Kann L, Kinchen S, Shanklin S, Flint K, Hawkins J, Harris W, et al. Youth risk behavior surveillance United States, 2013. MMWR Surveill Summ. 2014; 63(4): 1-168.

7. Downing J, Jones L, Bates G, Sumnall H, Bellis MA. A systematic review of parent and family-based intervention effectiveness on sexual outcomes in young people. Health Educ Res. 2011 Oct; 26(5): 808-33.

8. Kirby D. The impact of schools and school programs upon adolescent sexual behavior. J Sex Res. 2002 Feb; 39(1): 27-33.

9. Shrestha RM, Otsuka K, Poudel KC, Yasuoka K, Lamichhane M, Jimba M. Better learning in schools to improve attitudes toward abstinence and intentions for safer sex among adolescents in urban Nepal. BMC Public Health. 2013 Mar; 13: 244-53. Available from: www.ncbi.nlm.nih.gov/ nlmcatalog/100968562

10. Peltzer K, Pengpid S. Prevalence and social correlates of sexual intercourse among school-going adolescents in Thailand. ScientificWorldJournal. 2011; 11: 1812-20. Available from: www.ncbi.nlm. nih.gov/nlmcatalog/?term $=\% 22$ ScientificWorldJournal $\% 22$

11. Ruangkanchanasetr S, Plitponkarnpim A, Hetrakul P, Kongsakon R. Youth risk behavior survey: Bangkok, Thailand. J Adolesc Health. 2005; 36(3): 227-35.

12. Department of Health, Bureau of Reproductive Health. The situation of reproductive health among adolescent and youth. Nonthaburi: Bureau of Reproductive Health; 2016.

13. Department of Disease and Control, Bureau of Epidemiology. Thailand national guidelines on HIV/AIDs treatment and prevention 2017. Nonthaburi: Bureau of Epidemiology; 2017.

14. Vuttonont U, Greenhalgh T, Griffin M, Boynton P. "Smart boys" and "sweet girls"-sex education needs in Thai teenagers: a mixed-method study. Lancet. 2006 Dec; 368(9552): 2068-80.

15. Riley D, Sawka E, Convey P, Hewitt D, Mitic W, Poulin C, et al. Harm reduction: concepts and practice: a policy discussion paper. Subst Use Misuse. 1999 Jan; 34(1): 9-24.

16. Roosa MW, Christopher FS. Evaluation of an abstinence-only adolescent pregnancy prevention program: a replication. Fam Relat. 1990; 39(4): 363-7.

17. Bualoy W, Therawiwat M, Vathanasomborn P, Imamee N. Effectiveness of a sex education program to prevent sexual risk behavior on grade 8 students, Sampran district, Nakhon Pathom province. Rama Nurs J. 2014; 20(1): 127-42.

18. Grossman JM, Tracy AJ, Charmaraman L, Ceder I, Erkut S. Protective effects of middle school comprehensive sex education with family involvement. J Sch Health. 2014 Nov; 84(11): 739-47.

19. Cupp PK, Atwood KA, Byrnes HF, Miller BA, Fongkaew W, Chamratrithirong A, et al. The impact of Thai family matters on parent-adolescent sexual risk communication attitudes and behaviors. J Health Commun. 2013; 18(11): 1384-96.

20. Jerves E, López S, Castro C, Ortiz W, Palacios M, Rober P, et al. Understanding parental views of adolescent sexuality and sex education in Ecuador: a qualitative study. Sex Educ. 2014 Jan; 14(1): 14-27.

21. Duangmahasorn S, Srisuriyawet R, Homsin P. Effects of positive development program on attitudes toward premarital sex, perceived self-efficacy and intention to refuse premarital sex among early adolescents. J Nurs and Education. 2015; 8(1): 85-98.

22. Paknoi K, Krungkripetch N, Homsin P. Effects of life skills enhancement program on perceived self-efficacy and outcome expectancy to avoid sexual risk behavior among female lower secondary school students. J Nurs and Health Care. 2017; 35(3): 56-68. 
23. Neranon V, Phuphaibul R, Konsaktrakul C. Effects of the activity package computer game media on attitudes, norms and perceived behavior control on sexual abstinence of 7 th grade students. Kuakarun J of Nurs. 2018; 25(1): 73-89.

24. Widman L, Choukas-Bradley S, Noar S, Nesi J, Garrett K. Parent-adolescent sexual communication and adolescent safer sex behavior: a meta-analysis. JAMA Pediatr. 2016 Jan; 170(1): 52-61.

25. Secor-Turner M, Sieving R, Eisenberg M, Skay C. Associations between sexually experienced adolescents' sources of information about sex and sexual risk outcomes. Sex Educ. 2011; 11(4): 489-500.

26. Beech S, Sayer L. Analysis of sexual health care provided by school nurses. Prim Health Care Res. 2018; 19(3): 288-300.

27. Westwood J, Mullan B. Knowledge of school nurses in the UK regarding sexual health education. J Sch Nurs. 2006; 22(6): 352-57.

28. Dickson E, Lobo ML. Critical caring theory and public health nursing advocacy for comprehensive sexual health education. Public Health Nurs. 2018 Jan; 35(1): 78-84.

29. Vuthiarpa S, Sethabouppha H, Soivong P, Williams R. Effectiveness of a school-based cognitive behavioral therapy program for Thai adolescents with depressive symptoms. Pacific Rim International J Nursing Res. 2012; 16(3): 206-21.

30. Liu W, Dennis JM, Edwards CP. Chinese parents' involvement in sexuality education for adolescents. Int J Sex Health. 2015; 27(4): 485-507.

31. Villaruel AM, Loveland-Cherry CJ, Ronis DL. Testing the efficacy of a computer-based parent-adolescent sexual communication intervention for Latino parents. Fam Relat. 2010 Dec; 59(5): 533-43.

32. Rogers AA. Parent-adolescent sexual communication and adolescents' sexual behaviors: a conceptual model and systematic review. Adolescent Res Rev. 2017; 2(4): 293-313.

33. Atwood K, Zimmerman R, Cupp P, Fongkaew W, Miller BA, Chookhare W. Correlates of precoital behaviors, intentions, and sexual initiation among Thai adolescents. J Adolesc. 2012; 32(3): 364-86.

34. Rhucharoenpornpanich O, Chamratrithirong A, Fongkaew W, Miller BA, Cupp PK, Roseti MJ, et al. Parent-teen communication about sex in urban Thai families. J Health Commun. 2012; 17(4): 380-96.

35. Powwattana A, Thammaraksa P. Culturally-grounded mother-daughter communication-focused intervention for Thai female adolescents. Nurs Health Sci. 2018; 20(2): 214-23.

36. Suvarnakuta P, Congkhaow T, Nichachotesalid P. Effects of program to develop mother's skills in communication about sex with early adolescent daughters. J Prapokkloa Nurs College. 2015; 26(1): $1-16$.

37. Thipsungwan K, Srisuriyawet R, Homsin P. Effects of mother-participating program on sexual communication between mother and early female adolescents. The Public Health J of Burapha Univ. 2013; 8(2): 77-88.

38. Ajzen I. The theory of planned behaviour: reactions and reflections. Psychol Health. 2011 Sep; 26(9): 1113-27.

39. Chareonsuk J, Phuphaibul R, Sinsuksai N, Viwatwongkasem C, Villarruel A. Development of the causal model of young Thai female adolescents' sexual abstinence intention. Pacific Rim International J Nursing Res. 2013; 17(4): 329-41.

40. Fongkaew W, Settheekul S, Fongkaew K, Surapagdee N. Effectiveness of a youth-led educational program on sexual and reproductive health for Thai early adolescents. Pacific Rim International J Nursing Res. 2011; 15(2): 81-6.

41. Department of Health, Bureau of Reproductive Health. Reproductive health situation in adolescent. Nonthaburi: Bureau of Reproductive Health; 2016.

42. Niamkan S, Sornchai S. Factors related to communication regarding sex matter between parents and their puberty children. J Prapokkloa Nurs College. 2013; 24(2): 36-46.

43. Frison L, Pocock SJ. Repeated measures in clinical trials; analysis using mean summary statistics and its implications for design. Stat Med. 1992 Sep; 11(13): 1685-704.

Effectiveness

of the Dual Approach Program 
44. Krinara $P$, Ketvatimart M, Maneechot M. The effects of nursing student-lead unplanned pregnancy among early adolescents. J Boromrajnani College Nurs, Nakhonratchasima. 2013; 19(2): 20-30.

45. Taikanong K, Chomson S, Nimitranan N. The factors influencing the intention of sexual risk behavior among high school students. Christian Univ Thailand J. 2011; 17(1): 168-77.

46. Olanratmanee B, Jungsomjatepaisal W. The effect of comprehensive sex program on knowledge and skill of condom application to model of 2nd grade high school. J Nurs Sci. 2017; 35(1): 48-60.

47. Thongnopakun S, Pumpaibool T, Somrongthong R. The effects of an educational program on knowledge, attitudes and intentions regarding condom and emergency contraceptive pill use among Thai female university students. J Health Res. 2018; 32(4): 270-8.

48. Singchungchai P, Suwannarat W, SUkhapan U, Bunsong S, Hassman N, Bunlert K, et al. Effects of a sex education program for parents on their communication about sex with their teenage children. Songkla Med J. 2009; 27(1): 11-19.

49. Phuphaibul R, Promneramit P, Hattakitpanichakul K. "The Birthday Box" project: effects of parental participatory program on parental sexual communication intention and sexual communication behavior to their children. J The Royal Thai Army Nurses. 2018; 17(2): 12-20.

\section{Corresponding author}

Rutja Phuphaibul can be contacted at: ruja.phu@mahidol.ac.th

For instructions on how to order reprints of this article, please visit our website: 